TITLE: ON THE FACE OF FACEBOOK: HISTORICAL IMAGES AND PERSONHOOD IN FILIPINO SOCIAL NETWORKING

\author{
AUTHOR: Deirdre McKay \\ Senior Lecturer in Geography \\ Earth Sciences and Geography \\ William Smith Building \\ Keele University \\ Newcastle-under-Lyme \\ Staffordshire U.K. ST5 5BG \\ d.c.mckay@keele.ac.uk
}

\begin{abstract}
Exchanging and manipulating digital images on social networking sites offers people new ways renegotiate a wide variety of relationships. This paper examines how interactions on Facebook transform personhood and norms for relationships and belongings among a particular group of Filipino users. By tracking historical images that index users' profiles, the argument charts the simultaneous modes in which digital photographs act in on-line social networks. Following historical photographs that index users' profile, I show how these photographs are more than simply objects and instruments. Users' profile photographs also act as aspects of others and of the self - aspects mediated by reciprocal display, the content of the images and their histories of circulation.
\end{abstract}

KEYWORDS: Philippines, diaspora, Facebook, digital images, personhood

\title{
THE IMAGE VANISHES
}

Facebook and other social networking sites - MySpace, Bebo, Friendster and the like - have global popularity. Facebook approaches half a billion users worldwide. A Facebook corporate spokesperson may describe the site as "all about being a reflection of real-world relationships" (Slatalla 2007:1) but different groups of users engage in a wide variety of interactions through the site, not all of which simply 'reflect' off-line interactions. Instead, social networking technologies are inevitably transforming everyday life. Users and 
observers in the UK and US have voiced widespread concerns that these sites are producing worrying new norms for personal revelation, indiscretion, bullying and alienation. Instead of merely re-presenting already-familiar forms of personhood and relationship, these sites transform the ways people understand themselves. Digital images work to track and shape their interactions with others in novel ways. On Facebook, digital images reveal these transformations in personhood and norms for relationships.

Facebook images matter in everyday life, as this exchange overheard on a bus leaving my university campus in October 2009 shows:

“They've broken up before, but this time I think it's for real. Really over. He's deleted her on Facebook."

"How do you know?"

"I checked his 'friends' list - she's gone."

What's 'gone' is her photograph. Either an image of her face or an image she has chosen to represent herself has vanished from the list of 'friends' and the comments on his Facebook profile.

'Friends' are pairs of users who have exchanged their profile images to form the on-line relationship. One user initiates the exchange with a 'friend request' and the other accepts their invitation. The second user establishes the 'friend' relationship by reciprocating with their own profile image. The 'friends' relationship on Facebook can symbolize and extend previous or newly formed off-line relationships, or mark a completely new relationship between previously unacquainted persons. On-line 'friends' might be off-line romantic partners, siblings, children, neighbors, colleagues, schoolmates, clients, contacts made on holidays etc. Being 'friends' on Facebook can deepen and/or replace the time and co-presence necessary to sustain face-to-face relationships off-line. Profile images, along with the names that travel with them, mark a user's virtual presence in social networking's collectivities, hence the name 'Facebook.' Profile images appear on 'friends lists' on individual owners' pages and among collections of users who 'like' a company page or who are 'attending' an 'event' page. Reciprocally, the image of the 'friend' or company appears on the user's own profile. Reciprocal display digital images makes the 'friends' or 'like' relationship. Facebook makes these images visible to a much wider community 
of site users. Though some have described being Facebook 'friends' as a "lightweight" form of "relationships maintenance" (McClard and Anderson 2008:10), Facebook compels users to make these dynamic personal relationships continually visible. On Facebook, the on-line actions of 'friends' reveal 'friend' relationships to be simply tokens of recognition or virtual markers for long-term relations off-line involving mutual exchange of gifts, favors, opinion, affect and support which often have off-line dimensions. Users can find maintaining their 'friends' relationships hard work and high maintenance. In addition, they often feel a need to track activity on the site continually in order to learn of evolving connections and disconnections in their social worlds. Facebook generates a compulsion to visibility among users because it offers new ways to display and manipulate images on-line.

Together, digital imaging technologies and social networking sites allow people to share photographic images widely and instantaneously, attach text to images in several different ways, and contextualize images within their social network interactions. On these sites, new norms for privacy, discretion, bullying, intrusion and copyright infringement are emerging, many of which hinge on the production, visibility, exchange, ownership and interpretation of digital photographs. At the same time, technologies for producing, accessing, modifying, selecting, and storing digital images on social networks have expanded the possibilities for attaching images to selves. These technologies digital cameras, camera phones and video cameras have become much more accessible to and affordable for Facebook users. People have long used print photographs to attempt to take possession of spaces in which they feel insecure (see Sontag 1977:9). In the new on-line space of social networks, digital photographs take on this same role. By presenting a self through photographs, a user can claim features of a photographic context, environment or history to suggest aspects of the images reflect their own personal dispositions, aesthetic understanding, or cultural sophistication. Lury (1998: 3) describes this as photographs attaching a 'prosthetic biography' to the user. Photographic images express the culture of their producers and collectors through their choice of a "finite and well-defined range of subjects, genres and compositions" (Tagg 1988: 63, quoted in Pinney 1997: 11.) Together, social networking sites and digital 
images enhance opportunities for users to cite and display familiar (and novel) subjects, genres and compositions to express various facets of the self - linked to various relationships - and to engage in cultural critique. Displaying images allows users to bring together aspects of the self usually separated in space and time. Thus sites like Facebook both amplify and complicate the possibilities of exchange and display, juxtaposition and comment, cultural production and self-shaping that give photographic images their varied social meanings. By following a specific group of users and selected images on Facebook, this paper explores how social networks can transform personhood and belonging. My field site here is a Facebook newsfeed produced by forty-three respondents from previous research in and around Baguio City who are now my Facebook 'friends.' Thinking about who is - and is not - a 'friend' on-line - and with what images they represent their presence is central to my current project studying religious social networks among Filipinos in the UK. I was struck by the number of my Filipino friends and 'friends of' who had historical images for their profiles on Facebook. My Canadian, British and Filipino friends all post photographs of themselves as children, but my Filipino connections also post numerous historical images from their extended families and hometowns on Facebook, many of which have indexed their user profiles. First, I examine the general exchange of digital images, then the set of images that index Facebook profiles, before exploring the issues of historical images as profile photographs. Describing the production of and expectations for profile images contextualizes historical photographs in the set of images that travel with and precede them in users' experiences of Facebook. I then bring together anthropological approaches to social networks and theories of relational personhood with insights from ethnographic observations to suggest specific ways photographs work among my particular group of Filipino users. Finally, I explore my respondents' use of particular historical images before drawing a more general and preliminary - conclusion.

The profile photographs I describe are available to either all Facebook users or are restricted to friends of friends (a user viewing 'friends lists' cannot tell which setting the owner of a profile has selected.) I protect my respondents' anonymity - other than where my key respondents have agreed to be identified 
by name - by using pseudonyms and neutral pronouns. ${ }^{1}$ Some of the exchanges I describe involve practices infringing on either copyright or evolving local norms for customary ownership. Discussing these sensitive issues of ownership, I rely on interpretations of the others' actions collected through interviews with key respondents, including copyright holders. My argument draws these observations together with insights gleaned from Facebook activities, postings and email correspondence with my broader group of on-line respondents.

\section{DESIGN, IMAGES AND 'SPIRIT'}

The dynamic architecture of social networking shapes the ways people interact and portray themselves online. This architecture enables users to articulate public identity and present their relationships in new ways, while simultaneously enhancing the importance of creative play as a strategy of sustaining social interactions (boyd 2004.) Unlike competing sites MySpace and Friendster, Facebook works not through page content, but by reporting social interactions between individuals and groups (McClard and Anderson 2008:10.) Facebook uses images to enable "low maintenance, automatically generated, interaction-based content creation" (McClard and Anderson 2008:10). Initially launched as a site restricted to college students, Facebook opened up to the general public in 2006. By the mid-2010, Facebook had nearly half a billion users, with much of its growth due to an influx of users in the over-25 demographic (McClard and Anderson 2008:10) and from nationalities beyond its original American membership.

Profile images index all other text and image content on Facebook. ${ }^{2}$ These images are live links in other users' 'friends lists' and newsfeeds or page comments as a live link (boyd 2004). The architecture of the site anticipates users' profiles will show a picture of their face and thus 'friends lists' should appear as a collection of faces. Facebook indicates this to users by providing a null image for every profile. A white male head in silhouette on a blue background is the default 'face' of Facebook. This architecture means that anything - amusing drawing or historical photograph -stands in for a user's face in a profile picture. 
Images and their exchange are the daily drivers of Facebook interactions. There are also applications - a growing set of games and quizzes and virtual gifts - that expand the possibilities for interactions, playful self-disclosure and selfpublicity, while offering commercial opportunities and creating collective content (boyd 2004; McClard and Anderson 2008:10). Many applications attempt to enable users to discover and reveal heretofore hidden aspects of themselves. They also share users' personal data with their third-party designers who operate outside Facebook. McClard and Anderson's (2008:12) interviewees considered the "static likes and dislikes, education and demographic information.... [on profiles - DM] was less for 'friends' and more to feed the Facebook advertising model" that revolved around applications. Evident connections between embedded advertising, applications and the introduction of charges for the exchange of virtual gifts saw applications fall out of favor with some user groups. At the same time, numerous users mistrusted of the uses that applications - and other users - might make of their personal information. They demanded - and received - improved privacy filters. These users shifted back towards dyadic interactions mediated by image exchanges, published on newsfeeds and opened up to others' comments.

On Facebook, a profile image indexes comments, postings, links, likes and groups joined (but not personal emails) all of which perform on-line identity. Facebook reports all of these activities to friends in a rolling newsfeed, making the profile image particularly important. This images need to be unique and evocative, but accessible and interesting to others. Users typically select profile pictures to be novel and engaging, yet easy for others to discern when reduced to a small size. Most profile images are portrait photographs that seem to be rich sources of information on the owner, offering suggestions of the user's motives on the site, physical appearance, work or leisure interests, family relations, drinking habits, and attributes such as quirkiness or sense of humor. People the user may not know and may never meet see their profile picture. Activities on the newsfeed, 'friends lists', and 'likes' as well as text comments pages are seen by friends and friends' friends, all Facebook members, or even the wider internet, depending on the privacy settings the user has selected and the status of the page on which the picture appears. The newsfeed on a user's Facebook 
'home' page offers a stream of visual information - profile images and other digital photographs - accompanied by small chunks of text. All this makes a new profile image 'news' in itself, while changing and varied profile images can perform a user's identity as dynamic and fluid, or at least multiple in its aspects.

Most images selected for profile photos come from a broader field of digital photographic practices. Users tend to choose images from among those accumulated on personal digital cameras, video and cell phone cameras. Sometimes they upload drawings or symbols, scan their own material, or copy ('rip') electronic images shared by others. Making personal digital images requires a particular affective state to impel their production. People need to have what one of Voida and Mynatt's (2005a: 2) respondents calls "spirit" to take photos to post on-line.

"(O)nly when you have the vacation and have the time, you enjoy it... to share the pictures... [that] (s)pirit makes some nice pictures, and say(s) 'Look what I see today..." 3

This spirit waxes and wanes. Its temporality means most personal digital images are of family gatherings, life course events, socializing and holidays. Facebook photos generally conform to these social and seasonal genres, showing continuity with established photograph practices among amateur photographers in the West and elsewhere. When posting, users typically only choose a few images from the available pool. Most digital photographs languish in storage, never seeing display or publication, much like many old negatives and prints. Historical images require a different application of effort in their acquisition and display. Users scan historical images from photographic prints, solicit them as digital files from consociates or 'rip' them from other web-based content, including archive and local history websites.

In a study of digital images, Merrill (2005: 1) argues that sharing images is pleasurable and intensifies connections on social networking sites. If true, this pleasure is sometimes fraught with anxiety and discomfort. Privacy settings enable users to choose between potentially disclosing themselves to strangers or restricting their networks and activities by holding images back from exchange. Displaying images enables users to review and communicate past experiences with others, create shared and playful narratives, express affection, and create 
their own art (see Merrill 2005). These positive aspects of image sharing attract users and maintain their interest in Facebook. However, sharing images can also lead to confusion, distress, humiliation and alienation. Digital images - including digital photographs - can act in a wide variety of modes simultaneously. Voida and Mynatt (2005b) identified six ways in which digital images work within broader online communications. They found images amplify - in the same way as emoticons, cartoon characters etc. - accompanying text. Images can narrate telling a story in themselves. People also use images to express or heighten awareness of feelings. Some images bound a local subculture by acting as a kind of shorthand that is inaccessible to outsiders. Images can also invite others to interact. Lastly, they found images worked as objects or instruments when people sent others pictures of objects they own or of objects that have, for them, a particular symbolic importance. All of these modes identified by Voida and Mynatt (2005b) - and more, as I will show below - occur in image exchanges on Facebook.

\section{EXCHANGING DIGITAL IMAGES: ETHNOGRAPHY}

The Filipino Facebook users I interacted with in late 2009 - early 2010 were between 20 and 73 years old and have between 20 and 1,247 on-line 'friends.' Most of these users are middle and upper middle-class, college or university educated, and self-consciously cosmopolitan. Compared to Filipinos using Friendster (a site that has been much more popular with younger Filipinos), Facebook users have more non-Filipino friends in the mix, including me. ${ }^{4}$ Overseas connections, whether Filipino migrants, sojourners or emigrants and foreigners form are a key part of a diasporic and intercultural on-line space. Their Facebook 'friends lists' included parents, children, uncles, aunts and extended senior or junior kin, including off-line friends' parents, many living outside the Philippines. ${ }^{5}$ Unlike users in the US and UK, where Facebook reports on friendships that appear far more peer-focused and place-limited, Filipino Facebook profiles are directed towards extended family and long-distance connections. Just as off-line, beyond their young adolescent barkadas (cliques), they interact in multi-age groups connected by kinship - real or fictive propinquity and common interests and 'friends lists' showed both groups. Most 
of the images they posted in albums and on walls were the expected vacation snapshots and pictures of life course events like weddings, christenings and graduations. Facebook enables them to stay in touch with family, classmates, neighbors and to form virtual communities of various kinds, including recruiting for arts performances and exhibits and organizing relief activities after the October 2009 floods and landslides. Only one still experimented with applications, most having removed them in early 2009 for privacy reasons. Virtual gifts had also fallen out of favor now that the site required payment for them. Instead, they exchanged images, renewing their profile pictures several times each month or even each week, with the move away from gifts intensifying the rate at which profile images changed and circulated. Users who changing their profile photos usually accompany the new image with a new text 'status update,' but could alter either without changing the other. New photographs, however, always garnered a prolonged and more numerous series of comments than new status update text alone.

Their profile photographs tended to alternate between amusing shots of the person, images of landscapes in which they are sojourning or dwelling, their own aesthetically-pleasing photographs of landscapes, pictures of their families, particularly children, and shots of holidays and adventures. Given their migration and regular travel, these pictures were just as likely to feature village or beach scenes from the Philippines as they were to depict cityscapes from the US and the UK. These changing profile photos balanced the silly and the serious performing selves that are not taken too seriously, but take the world seriously showing a mix of humility and self-expression. Thus, they occasionally removed posts and images they deemed inappropriate, usually involving excessive exposure of bare flesh or alcohol. Since my 'friends' are mainly Ilokano speakers, they ought to feel alumiim - the need to anticipate how others will react to their actions first, in order to avoid embarrassment. Despite the language terms, I suspect this practice of reviewing images is no different from concerns negotiated by other users in similar demographics, though I suspect many groups of Western users may be less concerned about how they appear to others and less focused on others' feelings. 
These profile photos are visible to friends of friends or all Facebook users, depending on privacy settings. Many respondents were uncertain of who, in their social circles, would have access to Facebook and when, because of the staggering of arrivals on the site. A few tried selecting 'friends only,' but off-line friends were unable to find them, restricting the pleasure they could draw from participating. Yet having an accessible profile meant they felt obliged to accept almost all 'friends' requests, particularly when these came from senior kin and older family friends. As well as changing their profile shots, they tag friends in photo images and in 'non-image' photos (landscapes, usually) to draw 'friends' attention to particular images. All these techniques rely on images to iterate and thus sustain relationships; visual information swamps their newsfeeds. Frequent image exchanges map particular relationships as more intensely connected than others. Some relationships show intense activity around image of specific events, and then attenuate. Others relationships are maintained regularly. Linking people's names to specific images through tagging, comments, reposting or 'like' postings expresses the affective dimensions of these relationships publicly.

I tracked my respondents' profile images from September 2009 to August 2010. I found historical photographs appeared in a mix of contemporary settings and scanned postings. For example, L's profile picture of September 2009 showed her posed in her family home in Baguio City, standing in front of a display of black and white family portraits on a table. Her picture attracted comments posted mostly by her relatives in the United States. They congratulated her on the attractive photograph. They also enquired as to how they might obtain copies of the old black and white family photographs she displayed and offered reminiscences about the deceased relatives pictured. Other historical portraits and historic landscapes indexed the profiles of at least fifteen more of my friends at different times in late 2009/early 2010. They chose these images to alternate with contemporary photographs and selected photographs of historic landmarks (for example, Figure 1), and historical portraits, which appeared to colonial era postcards (Figure 2) or the work of Filipino photographer Eduardo Masferré (Figure 3). Scanning and sharing of historical photos, or producing new photographs of older photographic images, seemed to be about a different kind of 'spirit' than managing digital camera 
photos. On Facebook, this group wanted to bring into circulation not just an image of their quotidian life but one of the living past. Users juxtaposing or replacing what 'friends' expect to be a present image with a historical one suggest and re-present a specific relation between a past and their present. Using historical photographs as profile images draws an implicit equivalence between photographs of the self as against photographs attached to the self.

\section{PERSONHOOD AND PHOTOGRAPHS}

Profile images tell us about photographs and personhood. Photographs in 'friends lists' situate the person behind them at the centre of a wide - and perhaps valuable - network that has the potential to expand further (boyd 2004: 3). Nevertheless, profile photographs are not always objects or instruments in the conventional sense of material that can be alienated and consumed while still retaining symbolic meaning. They can also behave as parts of persons. To explain how Facebook 'friends' relations work, anthropologists have turned to accounts of dividual personhood offered by the new Melanesianist ethnography.

Anthropological explorations of Facebook draw on theories of the person developed in the new Melanesianist ethnography that emerged in the 1980s and 1990s, specifically on the work of Marilyn Strathern. Dalsgaard (2008:8) argues that social networking sites offer technologies that exhibit Western individuality but in forms that mirror forms of sociality prevalent in Melanesia. In this analysis, Facebook offers not a new form of personhood in itself, but reveals a potential for something akin to Melanesian dividuality (see Dalsgaard 2008: 10, note 2). Over the last few centuries, Western societies have repressed this potential by emphasizing and rewarding individualism. Facebook's digital collections of 'friends' demonstrate how persons are made up of relationships by displaying the images other users provide (Dalsgaard 2008 after Strathern 1988.) It follows that the digital images provided by friends on the 'friends list' are akin to the partible-person parts of Melanesian dividuals. Tracking the content and fate of these digital photographs on Facebook allows both observers and participants in these image exchanges to generate and criticize norms for personhood and relationships, both on and off-line. What follows, too, is that the 
revelatory aspects of this technology also then transform the norms they generate (see Slater and Miller, 2000).

Images and exchanges make visible iterative interactions sustaining users as persons - their constitutive relationships and identities. Even if this only reveals a clearer realization of the fundamentals of personhood, as Dalsgaard (2008) suggests, accepting this suggests a profound change in Western societies. Strathern tells us that Melanesian sociality builds up its character through repeated dissolution "into the ritual and exchange process of the main elements composing each individual" (Strathern 1992: 76, quoting De Coppet 1981: 176.) If we consider Facebook sociality to be an extension or representation of something called 'Western society,' continually revealing this dissolution at the level of image exchange enables Facebook challenge prevalent accounts of individual personhood. Though not Melanesians, Filipino personhood is not identical to the Western individual model. ${ }^{6}$ The legal, economic and social bounding (or un-bounding) of individual persons is, at least in part, an element of Filipino cultural heritage taken on under Spanish and then American colonial rule. Pre-colonial traditions nonetheless persist. In the Philippines, a classic text explaining the country to foreigners, Culture Shock: Philippines (Roces, 1992) contrasts Filipino and Western selves using the metaphor of fried eggs. Westerners are individual fried eggs whose edges do not touch; Filipinos are eggs fried together so that their whites blend, leaving a pattern of yolks embedded in a wider field. For my Filipino respondents, other people and their opinions and attributes as well as one's own history and ancestors seem to play a comparatively more prominent role within their accounts of the person. Thus, in the virtual spaces occupied by Filipino communities, it is not surprising that we find the anxieties and insecurities of a digital and diasporic age are being assuaged by importing images of and by others, and importing the past through historical images, not only of ancestors and past personal events, but of wider, historical, collectives. Along with this comes a conflicted attitude to copyright and ownership of historical images, compounded capitalist logics that rely on ownership and authorship vested in individuals or individuated actors like corporations. 
The Melanesianist approach thus suggests that the image of a face in a Facebook 'friends list' signifies the relationship of exchange to which its existence in a profile bears witness. ${ }^{7}$ Examining the specificities of Facebook profile images extends this analysis in useful ways. Facebook generates a category of familiar 'friends of.' These are people whose profile images a user sees regularly but whom he or she does not yet connect with - or at least not directly while on-line. Facebook then offers the user repeated opportunities to connect with them. The content of a profile image enables users to modify and limit these online interactions. Non-face images are 'local content'- cryptic and thus less inviting to friends of friends, thought they reinforce local identities among groups of offline consociates. The attributes, histories and status of the photographic images themselves are critical to the ways Facebook shapes personhood and relationships. Here, I do not want to not suggest too direct and mechanistic a mapping onto accounts of Melanesian exchange. The epitome of a Melanesian 'big man' dominates others by wealth, excelling in the competitive exchange of wealth. It does not follow that Facebook super-users - like my Filipino film-director friend with 1,247 'friends' - are able to sustain all these relations in quite the same meaningful way over time. While a big man's connections allow him to attract wealth to his next ceremony, long-distance updates will not necessarily garner a paying audience the director's next film, though they may help. The risks of expending energy in maintaining 'friends' relations may indeed be comparable, to some degree. Nonetheless, the two partners exchanging profile images are not involved in a classical gift exchange of material objects. Photographs here are not primarily objects and their recipients do not quite consume, then produce more and return them. The features of Facebook and digital images mean a 'friend' is better understood as a version of the dividual person who is the product of the propensities of Facebook itself, rather than as being equivalent to a big man's exchange partner. ${ }^{8}$ Reciprocal display does not really equate to Melanesian exchange, while profile images are not quite pigs.

Profile images are not themselves primarily material objects. Recent work on the materiality of photographs demonstrates that photographs simultaneously represent relationships and are material objects in themselves, 
carrying their own histories (Edwards et al., 2006; Wright 2004). This insight is relevant to understanding people's attachments to and use of historical images on Facebook. But, while profile images are sometimes made by scanning preexisting prints of photographs, their existence as digital code and their digital social life are most important to site users. Their owners can change digital images instantaneously, renewing them or, crucially, withdraw them unilaterally. When captured by downloading and printing, an image is no longer the 'friend' and thus moves into another realm of signification, perhaps as the photographs in the background of L's profile image, described above. Renewing the image with another variant and exchanging text around this renewal is what sustains the relationship. Removing the profile image entirely ends the relationship and, more often than not, marks its end offline, as well as on.

In negotiating relationships, the value of a Facebook image arises both from the image itself and from its grouping, collection, juxtapositions and the possibilities of citing past images, variation, modification and future connections to make new norms for persons and their relations. An emergent norm is that the absence of a profile photograph in a friends' list symbolizes a faltering romantic relationship. Avoiding on-line co-presence has emerged as a way of compartmentalizing things when partners are struggling. In two instances in late 2009/early 2010, I watched as more and more of one respondent and their partner's mutual social circle and extended families joined Facebook, appearing on 'friends lists.' In both cases, my 'friend's' romantic partner had no profile and was noticeably absent from all but a few photographs in their albums. There, they were not tagged. Lacking the 'spirit' to join Facebook suggested a lack of 'spirit' for more basic tasks of relationship maintenance. Evidently, the partner did find the relationship too demanding of time and affect. As the relationship broke up, the Facebook-user partner posted melancholy profile photographs and abstruse status updates. Their previous smiling, color portrait shots were replaced by grainy, black and white, scanned, historical images.

Posting these historical images and accompanying text was an exercise in 'local expression,' for those in their 'friends list' that shared the same childhood haunts and ancestors. Invoking nostalgia for a shared past suggested distress in the present, so these posts were troubling for other observers, who regularly left 
puzzled comments, expressing concern about the poster's emotional state. Both users, wanting to maintain some privacy, had selected the images as a kind of code to activate the support of close friends. Communicating a re-evaluation of roots and biography, of identity and connection, circulating the images made the work of mourning their break-up collective. To send this message, they selected ripped black and white photographs of old landscapes and portraits of themselves as children.

Using images this way shows how profile images index affect and suggests users seek out and appropriate historical images to convey particular emotional states. The second norm revealed here is that true friends among 'friends' must understand the personal, emotional language of photographs. Of course, the affect conveyed may only exist - present and future - as a projection by one partner in the many dyadic reciprocal exchanges of 'friends.' The tenuous quality of this affect means that the digital images in 'friends lists' haunt their collectors. Will exchanges of and around this image continue? Will this 'friend' or that respond to my changed picture? Once exchanges stop and profile images are removed, a relation can never quite be restored because the rupture has been made public, recorded and noted. Ruptures in exchanges reveal that, at the point where the network is cut (someone is deleted or someone refuses to join in), the power of social networking technologies to create new norms for relationship, and thus for extended personhood (Strathern 1988).

Among my respondents, then, historical profile images reveal extended and relational personhood. The images my 'friends' post map themselves through this wider field of Filipino personhood (Roces 1992) back into time. They post photos and join groups that share images of personal histories, culturally significant landscapes, ghosts and haunted sites, and photographs drawn from a variety of archives. Appropriating historical images to their profiles, they manipulate them with a self-conscious attention to colonial and personal histories. These appropriations reveal users' attempts to cultivate a personal aesthetic that maintains pre-colonial roots. They also show how users sustain a local orientation that nonetheless negotiates intimacy in relationships crossing national borders. It also offers new routes to ethnic and national 
belongings, with Facebook offering the possibility of 'friends' creating larger groups.

\section{NEGOTIATING BELONGING WITH HISTORIC IMAGES}

My respondents interact on and with Facebook pages established around the display and interrogation of historical images. ${ }^{9}$ Here, they share collective identities formed by juxtaposing profile images of those 'liking' the page with photographic content and posted comments. 'Liking' appears in the newsfeed, while links to pages 'liked' and page profile images appear on users' own profiles. After 'liking', they often select image content from these pages for their own profile images. Ripping these historical photographs for profile images marks users' profiles with images carrying established social cachet and historical, if not commercial, value. For migrants and residents of Baguio City, Facebook pages available in 2009/10 included Baguio City and Old Philippines. ${ }^{10}$ Both display historical photographs from the colonial era with approximately 22,000 and 100,000 'like' visitors respectively. ${ }^{11}$ Images from these pages have appeared as profile pictures on friends' profiles and in 'friends lists.' In this section, I follow three images to draw out important features of historical photographs and personhood on Facebook.

I found that this group of users understands historical photographs through a set of customary rules that are open to renegotiation. One example is the biography of Chito Francisco's digital photograph of the historic Laperal 'Haunted House' (Figure 1).

\section{[INSERT FIGURE 1 ABOUT HERE]}

Baguio citizens consider the house to be one of the city's iconic buildings. Four photos of it appear on Baguio City's Facebook page. Chito first posted his photograph on his Flickr feed. In our correspondence, Chito explained that the owners had seen it and contacted him to give him permission to publish the image. Two things are of interest here. First, the owners of the house understand they could object to the publication an image shot from the street. Secondly, Chito was contacted by email by someone he described as representing a family of owners with interests in the image. It is not necessarily the case that all those who consider themselves to have interests in the house were consulted in this 
extension of permission. Shortly afterwards, the Baguio City Facebook page then ripped the photograph for their albums without contacting Chito. Visitors to Baguio City then picked up the image to use it as a profile shot. Appropriating this image incorporates the city's 'spirits of place' and urban legends into a user's Facebook presence. For three of my respondents who are migrants or sojourners abroad, the photograph expresses homesickness and nostalgia for their hometown's past.

Image appropriations like this may or may not be within the broader intention of the sites' owners, who tend to see these collections as part of a nationalist project of identity (re)construction. Old Philippines, for example, has posted a "Company Overview" that explains images on the site are "for anyone," intended to be "interesting and useful" to those who "know and love the Philippines." 12 The site claims: "A nation's collective wisdom is rooted in its history.... What we are now is explainable with history. People having no pride in their past certainly have no future." Old Philippines' image of 'A Benguet Brave' (Figure 2) - seems to have spread across Facebook from an original posting on that site. A scanned version of the photograph appears among the page's profile pictures and has indexed five friend's profiles over the last year.

[INSERT FIGURE 2 ABOUT HERE]

Old Philippines identifies the photograph as dating to 1911 and taken from "an album that belonged to an American army officer who was posted in the Philippines in the early 1900s." The image resembles those of Filipinos taken for the 1904 ethnological survey of the Philippines. Visiting and resident Americans and then local photographers made similar photographs of sitters in 'tribal dress', posed in profile against an empty backdrop. Photographers printed these images as postcards and sold them to American troops, colonial administrators and visitors (Best 1994). If first published before 1923, American copyright law places these photographs in the public domain. Their history as postcards explains the frequent lack contextual information. Under this image, Old Philippines explains that the "writer of the label for this photo used the word "brave", a rather out-of-date term that used to mean an American Indian warrior." The text goes on to reminds viewers that ... "a significant percentage of the American soldiers involved in the Philippine-American war were also 
veterans of the latter campaigns of the Indian Wars (1870-1890) in the American West....The Philippines was an American colony from 1898 until 1946."

Beneath the photograph, 127 comments express pride in the resilience and courage of Filipino ancestors, discuss stereotypes of Philippine ethnic groups and debate the sitter's ethnic identity. Occasionally visitors leave racist comments. Old Philippines has posted a warning that disrespectful comments will be removed. Some comments suggest that the picture depicts a man from the Gaddang ethnolinguistic group, rather than the Ibaloy group who owned Benguet. Others request details of the provenance of the photograph and the album. One requests permission to reproduce a cleaner scan of the photograph in a forthcoming book on the history of Filipino tattoos. ${ }^{13}$ Visitors offer comments the history of representations of Filipino ethnic groups - particularly Igorot, the pan-ethnic category of indigenous people to which Ibaloy and Gaddang groups belong. ${ }^{14}$ Some comments cite recent representations of Igorots in other media outlets and discriminatory comments by media figures, demonstrating both how the broader media constitute the Filipino diaspora (de la Cruz, 2009) and Facebook plays a role in users' negotiation of this broader mediascape. What Old Philippines offers is a space to share personal encounters with historical images with the intention to build shared interpretations of history and ethnicity that run counter to broader media narratives about the Philippines and Filipino identities. Comments let visitors challenge prevalent ethnic stereotypes and join a public debate without mediation from family connections, long-standing interpersonal ties or letters to the editor.

It seems that appropriating an image from the site expresses visitors' Filipino pride and their political views and commitments. On Facebook, users are deploying these images to create a distinctive temporal field of on-line national and ethnic belonging that retains the past, while looking towards the future (see Gell 1998: 239, quoted in Hirsch 2004: 20). Exchanging such historical photographs expresses aspects of themselves that justify their ongoing belonging to wider collectives of ethnicity or nation. Thus it is my friends' affective attachments to the versions of themselves they project onto historical images makes them the post-colonial, self-reflective Filipino the Old Philippines site is cultivating. Posting these images establishes their belonging beyond family and 
neighborhood, kinship and propinquity.

A similar but even more popular profile image is Figure 3 - a photograph taken by the esteemed Filipino photographer Eduardo Masferré (1909 - 1995). I counted this image indexing seven different friend's Facebook profiles at various points in 2009 - 2010. This image is a 1936 portrait of Lakay Gangaoan of dap-ay Bilig, Demang, Sagada, Mountain Province, (De Villa et al. 1988: 128). ${ }^{15}$ The Masferré photographs are one of the most important collections of colonial-era photographs produced by an Asian photographer and the source of pride for many Filipinos. Many Filipinos, particularly those from the wider region around Baguio City whose ancestors were the photographer's subjects, consider Masferré images iconic examples of pre-colonial Philippine civilization. In addition, a large community of Filipino artists and photographers celebrate his skill and aesthetic. Masferré's gelatin silver photographs have been recognized internationally, appearing in the collections of the Smithsonian and the National Gallery of Australia, as well as being exhibited around the world and collected in two books (De Villa 1988 and 1999). The Masferré family retains the copyright to the images because, for post-1923 images such as these, the photographer and then his heirs hold copyright for 50 years after his death (De Villa 1999).

\section{[INSERT FIGURE 3 ABOUT HERE]}

Masferré's images circulated widely, long before they were collected as art. The photographer and his family sold prints of his photographs as picture postcards, largely to tourists visiting his studio in Bontoc, Mountain Province and later, visitors to the family's restaurant and home in nearby Sagada. In 1985, family members began to print the images on to T-shirts. The family now sell the images printed on to a range of bags, backpacks and T-shirts produced by Masferré Souvenirs, a company established in 2006, employing 20 workers. ${ }^{16}$ The company has a Facebook page of its own linked to an Eduardo Masferré Facebook page maintained as a tribute to the photographer by one of his heirs. The souvenir company's page shows visitors samples of the products and photos from a recent fashion parade, as well as offering an email address for enquiries and orders. The tribute page offers seven images - all among those published in E. Masferré - People of the Philippine Cordillera Photographs 1934 - 1956 (de Villa et al. 1988). ${ }^{17}$ Since the mid-1990s expansion of the internet, the Masferré family 
has had ongoing struggles with copyright infringement. In an interview, the photographer's widow, Mrs. Nena Ogues Masferré, explained their concern has been the production of derivative commercial products - souvenirs, greeting cards and artworks - that compete with their own products, rather than the circulation of reprinted images by enthusiasts of the art and the subjects it represents. Their history means it is no surprise these images appear as Facebook profile photos. While some Facebook users have 'ripped' Masferré's photograph of Lakay Gangaoan from the tribute page (or elsewhere on the internet) other have scanned and uploaded a postcard purchased from the Masferré family on a visit to Sagada. Several things may be happening to explain the image's history of continual appropriation.

Because photographs are material objects - bought, collected, mailed home and handed around - they become part of traveler's broader personal and family histories, even when those travelers are comparatively local. Having purchased the image, people may not be aware - or resist recognizing - that they cannot 'share' it on their profile without written permission from the copyright holders. Not everyone in the Philippines knows about or wants to respect copyright law, viewing it as an American colonial imposition. However, there do not seem to be any robust and agreed alternative notions of ownership and authorship. Instead, rights to borrow, use and circulated are negotiated from one instance to the next and the outcomes can depend on the prior history and status of the negotiators, economic considerations, and the apparent prestige attached to the exchange.

Postcolonial politics motivate other users who rip the image in a gesture of imagined political solidarity with those depicted in the Masferré portraits. The photographer came from a mestizo (mixed Spanish-Filipino) background and people assume he and the family have earned significant income, if not esteem, from the images, while the sitters' families have not benefitted. Equally, some choose the image because they admire and wish to emulate Masferré's photographic skill, choosing him as a truly Filipino photographer. Alternatively, others select the image for their profiles because they subscribe to Old Philippines' exhortation to show their pride in previously disparaged images of indigenous peoples and the pre-colonial past. 
Perhaps most interesting is the way that these portrait images act as aspects of the persons they depict. Some who 'borrow' the image are descendants of Gangaoan or relatives of his family or those who knew him before his death. They may resist complying with copyright because they feel he could not have understood just how widely - and, from his local perspective, comparatively profitably - the photograph he sat for might circulate. Like the Laperal family giving permission to a photographer to circulate photographs that depict their house, the family and friends of a sitter feel they have a residual right to delimit the circulation of his or her image. When that fails to be recognized, they appropriate the image to themselves as best they can. Relatives and friends can tend to attribute the success of the photograph more to the innate qualities of the sitter, rather than to the technical skill and aesthetic 'eye' of the photographer. Two of my respondents had selected Lakay Gangaoan's image for their Facebook profile because of their personal connections. One was a descendant living overseas who had accessed the image by 'likeing' the Masferré page while seeking an image from the family history. The other was an anthropologist colleague who scanned and uploaded a postcard image. Lakay Gangaoan had been among their favorite respondents in their first fieldwork in the 1970s. For the anthropologist, the image 'was' Lakay Gangaoan's presence and, because they'd had a particularly close relationship, it "felt good having him around." Mixed with the assertion that the photograph 'is' its subject is the idea that it is inalienably also part of the poster's self.

Some users thus appropriate historical photographs as aspects of themselves. The descendant considers the photograph part of a self that is composed by blood, inheritance and kinship. The anthropologist considers the photograph part of a personal/professional self composed by a career involving training, fieldwork, relations with respondents, teaching and other professional practice - a career in which Lakay Gangaoan's influence was formative. Importantly, this profoundly personal and expressive use of the image does not negate but instead works simultaneously alongside its cultural resonance and commercial value as object. The Masferré tribute page may be the site from which my friends have ripped the photograph of Lakay Gangaoan. Despite infringing on copyright, its continued circulation may be helping, rather than 
hindering the family business. Public visibility is what sustains the esteem in which Filipinos hold these photographs and their creator. The family thus has an interest in maintaining the cachet of these images and in keeping them prominent in the public imagination in order to expand the market for their souvenirs. On these Facebook pages, use of these historical images thus marks a move towards recognition of a form of personhood that extends beyond the legally recognized boundaries of the individual. As Mrs. Masferré explained, in each instance the family finds an copies copied, "we try to understand why they put the image there, on the internet or wherever... if it's to show their pride, we share the feeling, so can just request they stop. But if they will use the pictures to earn money... by making greeting cards or novelties... we need to act."

\section{CONCLUSION: IMAGES AND BELONGING}

Facebook is one of several new interactive technologies that shift users towards recognizing a more markedly relational self. The site enables users to deploy digital images in new ways and the images themselves become actors, shaping new modes of interaction and norms for relationships from kinship to romance to friendship to ethnic or national belonging (see Miller 2007). That new technologies shift users' perceptions of the self suggests individuality and dividuality are always present, but articulated differently in different cultural contexts and with varying emphasis. My respondents' desire to transfer extended family and collective histories onto Facebook implies a difference between the emphasis and articulation of the dividual and individual aspects of the person between Filipino and non-Filipino users. With Facebook offering such resources to negotiate personhood, relationship and belonging in new ways, it not surprising that post-colonial Filipino users contest understandings of ownership and appropriation of images they consider follow colonial norms.

I found my Filipino Facebook 'friends' using digital images in all the prosaic ways Voida and Mynatt (2005b) anticipate, with historical photographs as profile images being most important for bounding, invitation and exchanging symbols. Going beyond Voida and Mynatt's (2005b) category of appropriated objects/instruments of exchange, in this paper I have demonstrated how other modes of action enable historical photographs on Facebook to make visible 
personhood and relationships. It is not simply that photographs attach a 'prosthetic biography' (Lury 1998) to user's profiles by revealing something about the profile owner. Instead, ripping images allows users' to re-possess images they consider already parts of themselves. These appropriations express feelings and attachments and histories (real and imagined) that users believe others have yet come to recognize but - when others do recognize them - will create a broader community in which the user belongs. Here, historical photographs are not 'prosthetics' (Lury 1998: 3) attached to the self in a replacement role, filling in for something lost or never had. Instead, such images are intimately parts of selves, though their import and significance comes, in part from traveling through time - and cyberspace - with their own independent biographies.

\section{ACKNOWLEDGEMENTS:}

My thanks to my respondents among Filipino migrants in London and from previous (1995 - 1997 and 2005) research in the Philippines who are my on-line 'friends.' I am indebted to Mrs. Nena Masferré for her hospitality and to her, her son Jaime, and Jill De Villa for their reflections on the challenges of copyright. I am grateful to Chito Francisco and the Masferré family for permission to reprint their photographs. Daniel Miller generously offered me insights gleaned from his current work on social networking in the Philippines and Trinidad, while he, Ben Smith, Elizabeth Edwards, Richard Vokes, Marcus Banks and two anonymous reviewers provided helpful input on the paper's earlier iterations. All shortcomings remain mine alone. 


\section{REFERENCES:}

Afable, P. (1996) 'The people of Eduardo Masferré's photographs', Discovery, vol 2, pp. 11-19.

Best, J. (1994) Philippine Picture Postcards 1900 - 1920, Bookmark, Manila.

boyd, d. (2004) 'Friendster and publicly articulated social networks.' Conference on Human Factors and Computing Systems, Vienna [online] Available at: http://www.danah.org/papers/CHI2004Friendster.pdf (last accessed 31 August 2010).

Dalsgaard, S. (2008) 'Facework on Facebook: the presentation of self in virtual life and its role in the US elections', Anthropology Today, vol. 24, no. 6, pp. 8-12.

De Coppet, D. (1981) 'The life-giving death', in Mortality and Immortality, eds S. Humphreys and H. King, Academic Press: London, pp. 175-204.

De Villa, J., Farr, M. \& Jones, G. (1988) E Masferré - People of the Philippine Cordillera Photographs 1934 - 1956, Devcon IP Inc., Manila.

De Villa, J. (1999) E Masferré - a Tribute to the Philippine Cordillera, Brier Projects Inc., Manila.

De La Cruz, D. (2009) 'Coincidence and consequence: Marianism and the mass media in the Global Philippines', Cultural Anthropology, vol. 24, no. 3, pp. 445488.

Edwards, E., Gosden, C. and Philips, R. (eds) (2008) Sensible Objects, Berg, Oxford.

Gell, A. (1998) Art and Agency, Clarendon Press, Oxford. 
Hirsch, E. (2004) 'Techniques of vision: photography, disco, and renderings of present perceptions in Highland Papua', Journal of the Royal Anthropological Institute, vol 10, pp. 19-39.

Lury, C. (1998) Prosthetic Culture, Routlege, London.

Merrill, D. (2005) 'Ideas and considerations for digital photograph sharing.' Ubicomp '05, Tokyo, [online] Available at:

http://alumni.media.mit.edu/ dmerrill/publications/dmerrill UBICOMP2005 P ICS.pdf (last accessed 31 August 2010).

Miller, D. (2007) 'What is a relationship? Is kinship negotiated experience?', Ethnos, vol. 72, no. 4, pp. 535-554.

Miller, D. \& Slater, D. (2000) The Internet, Berg, Oxford.

McClard, A.\& Anderson, K. (2008) 'Focus on Facebook: who are we anyway?' Anthropology News, March, pp. 10 and 12.

Slatalla, M. (2007) 'Cyberfamilias: 'omg my mom joined facebook!!' The New York Times 7 June, [online] Available at:

http://www.nytimes.com/2007/06/07/fashion/07Cyber.html (last accessed 5 November, 2009)

Strathern, M. (1988) The Gender of the Gift, University of California Press, Berkeley.

Strathern, M. (1992) 'Parts and wholes: refiguring relationships in a post-plural world', in Conceptualizing Society, ed. A. Kuper, Routledge, London, pp. 75-104.

Tagg, J. (1988) The Burden of Representation, Macmillan, Basingstoke.

Pinney, C. (1997) Camera Indica, Reaktion, London. 
Roces, A. (1992) Culture Shock! Philippines, Graphic Arts Center Publishing Company, Portland.

Voida, A. and Mynatt, E. (2005a) 'Cameraphone inertia', Ubicomp 2005, Tokyo [online] Available at:

citeseerx.ist.psu.edu/viewdoc/download?doi=10.1.1.134.7492 (last accessed 31 August 2010).

Voida, A. \& Mynatt, E. (2005b) 'Six themes of the communicative appropriation of photographic images', ACM Conference on Human Factors in Computing Systems, New York, pp. 171-180.

Wright, C. (2004) 'Material and memory: photography in the Western Solomon Islands', Journal of Material Culture, vol. 9, no.1, pp. 73-85. 
LIST OF FIGURE CAPTIONS:

Figure 1: The Laperal 'Haunted House' along Leonard Wood Road, Baguio City, by Chito Francisco. (Source: Baguio City, facebook.com)

Figure 2: A Benguet Brave, 1911, photographer unknown. (Source: Old Philippines, facebook.com)

Figure 3: Lakay Gangaoan of dap-ay Bilig. Sagada, Mountain Province, 1936, by Eduardo Masferré. (Source: De Villa et al. (1988) p. 128) 


\section{NOTES}

${ }^{1}$ I do not provide screenshots of Facebook user profiles other than my own. Facebook's rules prevent alterations, thus requiring the consent of all 'friends' appearing in the image, some of who would be non-respondents.

${ }^{2}$ Embedded video and page links also appear initially as still images. 'Liking' something on a Facebook profile is more complex. When users 'like' a photograph or a comment posted by another user, Facebook does not index the activity with their profile photograph on that user's profile. Writing a comment of their own is indexed with a profile image and a user's privacy settlings determine whether the activity enters the newsfeed.

3 Voida and Mynatt (2005) do not offer detailed accounts of respondents' backgrounds and histories.

${ }^{4}$ Daniel Miller, pers. comm., June 2009.

${ }^{5}$ It would be fascinating to map this out more precisely, but would require offline interviews and more complex negotiations of consent than allowed by the time available.

6 'Model' here suggests an archetype, ideal or norm, rather than everyday practice or experience.

${ }^{7}$ After Strathern (1988) and thanks to Daniel Miller for clarifying this observation, pers. comm., June 2009.

${ }^{8}$ Daniel Miller, pers. comm., June 2009.

${ }^{9}$ Originally Facebook 'groups', these pages have become 'company sites' where, rather than 'joining', Facebook users 'like.' Visiting users see a small and varying selection of profile images for those who 'like' the content and are able to join and comment on the images posted by the owner.

10 Both at www.facebook.com.

11 Users could also join two now-defunct Facebook 'groups.' 'Kennon Road take me home: Baguio City' had two administrators and 1,207 members, and offered 243 historical images of the city and access to its members' list. Baguio Old

Times similarly offered historical photographs of Baguio City in the colonial era. Both have been removed from Facebook, possibly due to copyright concerns. No reason has been offered and contact details recorded for the administrators do not generate a reply.

12 Old Philippines on facebook.com. (Last accessed 12 June 2010.)

13 Old Philippines posted the photograph 12 August 2009, but the owner has yet to respond to any of these queries. The 'wall' on the page seems to be filling up with advertising, suggesting the page owner is no longer regularly maintaining the page.

14 For more detail, see Afable (1996).

${ }^{15}$ Sagada is a town in Mountain Province, Demang being one of its subdivisions. A dap-ay is a stone circle where male elders governed local communities through consensus and performed ritual (see Afable 1996).

16 See http://www.citem.gov.ph/catalogonline/main/copages.php?ccode $=6645$ (last accessed 31 August 2010)

17 Four of the seven images offered on the Eduardo Masferré Facebook page also currently appear in high resolution on another site, Robert S. Gardener's http://www.aenet.org/ifugao/masfere.htm (last accessed 31 August 2010.) 